\title{
El espacio simbólico: \\ el caso del teatro español del Siglo de Oro
}

Es posible que a muchos de los que nos dedicamos a la literatura antigua (la grecolatina, la de la Edad Media, la de los Siglos de Oro o la primera literatura colonial) nos sorprenda encontrar en la semiótica acercamientos al hecho literario que pueden coincidir con algunas de nuestras búsquedas. Nos ha pasado como a monsieur Jourdain, quien hablaba en prosa sin saberlo. Y quizá no únicamente aparezcan estas cercanías entre nosotros, sino en estudios muy primitivos. Tal es el caso del Pinciano, en cuyo texto (1596) puede uno leer cosas como éstas:

El libro que aora Iees, Fidentino tú le lees y entiendes, de manera que dexa de ser mío $y$ se hace tuyo. ${ }^{1}$

Asimismo, al meditar en la representación dramática, el Pinciano señala que los actores deben cuidar sus evoluciones en el escenario, pues el movimiento "del cuerpo, piernas, braços, ojos, boca y cabeça [...] según el effecto que se pretende" transmiten ideas al espectador. $Y$ prosigue el Pinciano: "en suma, assí como el poeta [esto es, el dramaturgo] con su concepto declara la cosa, y con la palabra, el concepto, el actor, con el movimiento de su persona, deve declarar y dar fuerça a la palabra del poeta". 2

1 Pinciano, Philosophia antigua poética, ed. Carballo Picazo, CSIC, Madrid, 1973 , t. XIX, Epistola treze, p. 281.

2 Ibid., p. 285. 
El Pinciano abunda en detalles sobre el signo gestual; se detiene en lo que podriamos llamar el lenguaje del movimiento de pies y manos. Dice, por ejemplo, de los pies, que en escena, "el tímido retira los pies, y el osado acomete, y el [osado] que tropieza passa adelante con su voluntad" y "las personas graves y trágicas se mueven muy lentamente; las comunes y cómicas, con más ligereza; los viejos, más pesadamente; los moços, menos y los niños no saben estar quedos"."

En todo lo anterior es perceptible la idea de sistema que produce significados. Se puede intuir también, por la homología que se hace entre el lenguaje del dramaturgo y la expresión corporal sobre la escena, la identidad de un lenguaje precisamente teatral que acompaña a la obra puramente escrita, pero que no se limita a apoyar al texto, sino que genera su propio campo semántico en escena: el movimiento de los pies expresa edad, condición social, aun origen geográfico del personaje; es, pues, un código.

Se podría proseguir esta pesquisa y hallar en otros críticos los rasgos de una presemiótica. Pero fuera cuento de nunca acabar. En última instancia, lo que interesa destacar en el ejernplo de Pinciano, es lo cercanas que debiéramos sentir ciertas búsquedas de la nueva disciplina semiótica en nuestra labor de investigación, dado que, según nos ha ocurriclo al leer la Philosophia antigua poética, es frecuente advertir que algunas inquietudes de la crítica más filológica se hallan referịdas en la ciencia de los semiólogos. Como puede verse, la semiótica no ha descubierto el interés crítico por la generación de signos en determinados dominios (la escena teatral, el movimiento gestual, el sistema de la moda del vestido, etc.) más bien ha intentado sistematizar su estudio, e ir más allá para indagar de qué manera se llega a producir significados.

El lenguaje de los pies es uno de los varios aspectos que muestran la escena dramática como productora de señales que deben ser descodificadas por el espectador. Otro que se juzga importante es el del espacio, quizá de mayor relevancia

3 Ibid., p. 286. 
que el anterior, por cuanto el teatro es un género fuertemente anclado al lugar de la representación. De su vinculación a la escena revela el género dramático sus limitaciones, pero también, en su amplia problemática espacial, evidencia las posibilidades de la práctica significante de la representación. De allí que dentro del teatro pueda descubrirse la tendencia de la escena a convertir o a mimetizar en espacio todo cuanto aparece en ella. No se trata sólo de descubrir la ingenuidad de que los actores ocupan un lugar sobre el tablado, sino de observar cuánto un personaje queda vinculado semánticamente a un espacio determinado, de manera que el carácter recibe connotaciones insólitas de la contingencia topológica: la esposa y la casa en un drama de honor, el pueblo común en la calle y la plaza, el proscrito - de fuertes caracteres de animalidaden el monte, en descampado.

De estos ejemplos - y otros más a los que habremos de aludir- surge una idea que puede concretarse en los juicios expresados por Yuri Lotman: los signos que manifiesta el espacio constituyen un sistema dentro del texto. La obra artística se vuelve "modelo de la estructura del espacio del universo, y la sintagmática de los elementos en el interior del texto en el lenguaje de modelización espacial"." Las oposiciones que Saussure descubrió en el lenguaje verbal, vuelven a encontrarse en la conformación espacial; de esta manera, según Lotman, se produce significación de los contrastes "afuera"/"adentro", "arriba"/"abajo", "abierto"/"cerrado", "próximo"/"lejano", etc.

Naturalmente, no es el teatro quien ha inaugurado esta forma de entender el espacio. Hay un código establecido por la cultura que distribuye las oposiciones topológicas y confiere sentidos axiológicos a esa distribución. Por esos juicios de valor, es que en la lengua común se habla de "clase baja", frente a la declaración de que Fulano es un "alto personaje de la política", por ejemplo. Aprendemos desde niños a preservar los espacios, según una organización que señala valores para cada 271 .

4 Yuri Lotman, Estructura del texto artistico, Istmo, Madrid, 1978. pp. 270 - 
caso: no sólo se prohíbe dejar los zapatos sobre la mesa del comedor, o llevar los cacharros sucios a la sala de estar, sino que se sacralizan ciertos lugares: la iglesia, claro, pero también la sala de conciertos, el Palacio Nacional, etc. Cruzar la línea de demarcación de un espacio es ya una trasgresión.

Dado el carácter del teatro de enfatizar los problemas espaciales, lo que la escena dramática hace es concentrar esos sentidos heredados, ya sea presentándolos por medio de la escenografía, o sugiriéndolos solamente en el discurso de los personajes -malicia del dramaturgo que suprime elementos de la representación para que, entonces, cobren el peso de lo adivinado. Esta vía diegética, que nombra los lugares sin mostrarlos, según la distinción hecha por Michael Issacharoff es igualmente importante que la mimética, la que muestra los espacios sobre el tablado.

En el desarrollo de la escena española del Siglo de Oro, como sabemos, hay una etapa primitiva, la de los corrales, cuando las representaciones eran esencialmente discursivas, con escaso o nulo movimiento escénico y de muy poca preocupación por representar y fijar los ámbitos. El ejemplo más claro de esta orientación diegética de la primera Comedia nueva está en su ausencia de interés en registrar acotaciones. Una revisión de pasada a las ediciones originales, las "Partes", publicadas en la época, nos constata esa evidencia: han sido investigadores que vinieron después - Hartzenbusch en el xIx y otros- quienes han llenado las ediciones que hoy manejamos de instrucciones para la puesta en escena, quienes, en fin, han dividido en escenas un texto que deliberadamente negó esa precisión. $^{6}$ En esta proclividad diegéticà de la primera Comedia nueva se observa ya esa estilización que hoy puede motivar la

5 "Space and Reference in Drama", Poetics today, 2: 1981, núm. 3, pp. 211224.

6 Ya el Pinciano -op. cit., p. 278- advertía que en cuestiones de decorado y movimiento teatral, "el actor deve hazer este escrutinio [...], porcule el poeta, las más vezes no haze cuenta desto, como quien escrive el poema para que sea lcydo más quie para que sea representado, y dexa las partes que atienden a la acción al actor". Subrayados míos. 
extrañeza en el espectador. No es la búsqueda del detalle que pueda ser reconocido lo que importa a Lope de Vega, por más que asegure en El arte nuevo de hacer comedias, 7 que el fin de la Comedia verdadera es "imitar las acciones de los hombres/ / y pintar de aquel siglo las costumbres". Es el pensamiento sobre la sociedad lo que desea proyectar el autor.

Pero el Calderón de la madurez hará amplio uso de las posibilidades visuales que le ofrece la nueva escenografía. Calderón de la Barca representa ya algunas de sus obras en edificios construidos expresamente para el teatro; el clramaturgo vio incrementarse en la corte el interés por las representaciones dramáticas y asistió, primero con reservas y más tarde con plena aceptación, al auge en Madrid de las revolucionarias técnicas de los escenógrafos italianos. A la vez, lo veremos preocupado, igualmente, por los medios que revela la otra vertiente dramática, la versificación. Las acotaciones calderonianas evidencian las nuevas necesidades de la escena; fijan y deslindan unos espacios de otros, refieren detalles nimios del ámbito dramático, y como en Leonido y Marfisa, se llega a una prosa en las acotaciones muy cercana a la que encontramos en el Valle Inclán de Divinas palabras:

Entrándose cada uno [de los personajes] por su parte, se mudó el teatro de bosque en uno que representaba firmes peñascos, fundados sobre las inconstancias de.las olas del mar, a quien oprimían, y ellas, ofendidas del grave peso, conjuraban sus espumas, azotando los hombros de las peñas con la impetuosa furia de sus raudales. ${ }^{8}$

La cualidad más diegética del primer Lope de Vega, nọ impide, sin embargo, reconocer ciertos espacios simbólicos

7 Utilizo la ed. de Juana de José Prades, CSIC, Madrid, 1771, P. 285, v. $52-53$.

8 Calderón, Hado y divisa de Lconido y Marfisa, I, p. 2103, ed. Valbuena Briones, Aguilar, Madrid, 1978, vol. II. En la "Nota preliminar", Valbuena Briones asienta que "Juan Eugenio Farzenbusch afirma que esta prosa interpolada debe pertenecer al mismo Calderón, ya que se halla con la comedia en el documento manustrito que se guarda en la Biblioteca Nacional [de Madrid]". Ibid., p. 2095. 
descle obras tempranas del Fénix (como Los hechos de Garcilaso) ${ }^{9}$ En esas primeras obras, como señala Díez Borque, uno debe oír lo que dice el personaje, a fin de localizar el lugar en que acontecen los hechos. ${ }^{10}$ Es dable, por tanto, si no observar los diversos sitios en la escena, imaginarlos y, lo que resulta más interesante, llegar a sus significados.

En el drama de honor, por ejemplo, la oposición adentro/ afuera, y su secuela abierto/cerrado cobran tal relevancia que las entradas de varones extraños a los interiores ocurre con disculpas a tamaño "atrevimiento"; asimismo, gran parte de los hechos tomados como adulterio por el marido se deben a la entrada subrepticia de un varón ajeno a la familia. La casa adquiere la importancia de la mujer, o para decirlo de otra manera, la casa repite los caracteres sexuales cerrados que se pretende tenga la mujer. El portador de la llave -o del anillo de bodas- es el único varón que puede penetrar ese recinto. Descle Los comendadores de Córdoba de Lope de Vega, se sitúa esta oposición topológica casa/descampado en el centro de las preocupaciones espaciales de los dramaturgos: se reúne a los personajes femeninos dentro de la casa - "la mujer en su casa y con la pierna quebrada", que dice el refrán-, en tanto que los varones circulan libremente en la calle, en el camino, en el mar. El marido guarda así, echando llave a la puerta, a la mujer, y con ella, el tesoro de su honor, la limpieza de su opinión. ${ }^{11} \mathrm{Si}$ vemos a una mujer en la calle, es porque, o está deshonrada y carece de varón que pueda pugnar por restituirle el honor, o porque viaja encubierta a reunirse con quien será su esposo. Sale muy temprano, como doña Leonor, la deshonrada:

פ Crr. Lope, Los hechos de Garcilaso y Moro Tarfe, "Nota prelimitar" en Obras escogidas, ed. Federico C. Sáinz de Robles, Aguilar, Madrid, 1962, col. I, tomo 2 p. 1202.

10 Díez Borquc, "Aproximación semiológica a la escena del teatro cspañol del Siglo de Oro", AAVV. Semiología del tealro, Planeta, Barcelona, 1975, pp. 76-77.

11 Cfr. Lope, Los comendadores de Córdoba, Obras escogidas, edl, citada, vol. I, tomo 2 p. 1235 . 
Salgo a misa antes del día porque ninguno me vea en Sevilla, donde crea que olvido la pena mía. Mas gente hay aquí. ¡Ay Inés!12

Puede ser también que la deshonrada se lance a los caminos a perseguir al galán, y elija vestirse de hombre, como Rosaura, la de La vida es sueño de Calderón, o como doña Juana en Don Gil de las calzas verdes, de Tirso de Molina. Hay en este cambio de vestido, además de otras razones específicas para cada caso, un problema de calificación de los espacios: si los exteriores son sitios esencialmente masculinos, la mujer, al invadir un ámbito contrario a su condición, debe mudar su ropaje para adquirir, de manera encubierta, el derecho a pisar un territorio que le está vedado.

Sin embargo, en El castigo sin venganza, Lope presenta el primer encuentro de Federico y Casandra, el hijastro y la joven madrastra, en descampado, no en interiores. Federico ha acudido al camino a esperar a la que será esposa de su padre. El carro en el que va Casandra, cae a un arroyo; Federico oye las voces de auxilio, se lanza a las aguas y saca en brazos a la dama. Los caracteres del espacio y los acontecimientos funden sus significados para hacer de esta escena un estupendo golpe teatral. El descampado, el lugar "ameno", se tiñe de connotaciones de peligro: la caída de Casandra adelanta la catástrofe que tendrá lugar en el 3er. acto, es decir, la muerte de los dos protagonistas del adulterio. La caída también señala una caída metafórica, la de Casandra, quien se dejará llevar por la pasión hacia su hijastro. Pero el espacio se contamina aún de otras implicaciones: el encuentro ocurre fuera de los muros interiores de la casa, que se asocia a la institución del matrimonio.

Para el hombre, la batalla, la aventura, la corte, pero sobre todo, el camino y el peligro, que lo sitúan en medio de la vida social, con todos los riesgos que ello significa. De aquí

12 Calđerón, El médico de su honra, IIr, rv. 2794-2798, ed. D. W. Cruickshank, Castalia, Madrid, 1981. 
se desprenden cualidades distintas en el pensamiento sobre el tempo para ambos sexos. El hombre que dibuja el teatro español del xuII no sólo es un ser de espacio exterior; también, frente a la inmovilidad de la mujer encerrada en su casa, el varón adquiere el ritmo del vivir apresuradamente. Recordemos la movilidad incesante de don Alonso, El caballero de Olmedo, el ritmo nervioso en que se suceden las aventuras amorosas de don Juan, El burlador de Sevilla. O la celeridad con la que vive aquel otro, el proscrito, el incestuoso, el Eusebio de La devoción de la cruz. Junto a esta imagen arquetípica, la figura del caballo revela su funcionalidad como vehículo de ese vivir aceleradamente, pero también como atributo casi sexual, como insignia viril del caballero. Las damas lo asocian con el amado, como doña Beatriz en Los comendadores de Córdova: el caballo cascabelea nerviosamente frente a la casa de la dama; inquieta, doña Beatriz exclarra:

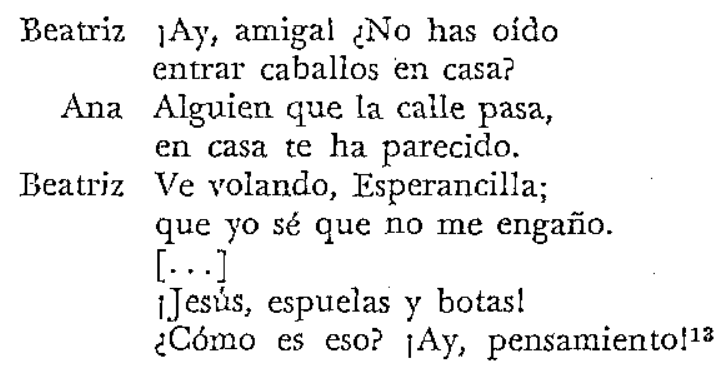

O como Mencía en El médico de su honra; allí la imagen ecuestre, se hace casi onírica, la fantasía erótica de los sueños de vuelo se percibe en forma gozosa: el jinete se hace uno con el bruto, hasta desaparecer, fundido en él por los aires:
un bizarro caballero en un bruto tan ligero, que en el viento parecía un pájaro que volaba;

13 Lope, Comendadores, II, p. 1243, ed. cit. 
y es razón que lo presumas

porque un penacho de plumas

matices al aire daba. ${ }^{14}$

El elemento del caballo es un elemento diegético, por cuanto resulta difícil llevarlo a escena; ello no resta a la figura equina su valor emblemático en el teatro como receptáculo de hazañas sin cuento en la historia cercana, de fuertes acentos épicos en la literatura (los romances, la epopeya, las novelas de caballerías). Esos significados culturales se asocian con tintes de erotismo o con implicaciones de la pasión desbordada que lleva al jinete a la caída de la montura. Otro supuesto sobre el espacio teatral que conviene observar en el teatro del Siglo de Oro es el de la distancia personal que guardan los protagonistas unos con otros. ${ }^{15}$

Según Edward T. Hall, antropólogo fundador de una ciencia a la que denomina proxémica, es decir, el estudio de la relación del hombre con el espacio, las diferentes culturas prescriben un ámbito personal variable para los individuos. A esta distancia la llama "territorio", basándose en la jerga de la etología. Se definen así, "especies de contacto", comunidades de nula o escasa distancia personal entre las personas, como la gente del III Mundo, y "especies de no contacto", como los alemanes y los norteamericanos. Hay también ciertos seres cuya investidura política o prestigio social los sustrae del contacto personal; los sacerdotes, los dirigentes políticos como los reyes, claro, son seres de "no contacto".16

Recordemos, para dar un ejemplo de territorialidad de un monarca, la visión de los Reyes Católicos que se da al final de Fuenteovejuna. Me refiero a la escena en la que Laurencia,

14 Calderón, El médico..., I, pp. w. 49-56, ed. cit.

15 Umberto Eco, "Elementos preteatrales de una semiótica del teatro", AAVV. Semiologia del teatro, Planeta, Barcelona, 1975, p. 101: "Quien ha leído libros como La dimensión escondida de Hall, sabe que no existe la más mínima alteración de las distancias espaciales entre dos seres que no tenga un significado diferencial."

16 Edward $x$. Hall, La dimensión oculla, Siglo XXI, México, 1979, pp. 14 y 21-24. 
Frondoso y el pueblo todo son llevados por el juez pesquisidor ante Fernando e Isabel para que los monarcas determinen qué se debe hacer con ellos, pues, a pesar de haberlos torturado, no se ha logrado saber quién mató al Comendador. Ante la vista de los reyes, Laurencia muestra un arrobamiento casi reverencial; se diría que asiste embelesada, pero distante, ante los mismos San José y la Virgen María:

\section{Laurencia ¿Aquestos los reyes son? \\ Frondoso $Y$ en Castilla poderosos. \\ Laurencia Por mi fe que son hermosos: ¡bendígalos San Antón!17}

No hay que olvidar que esta escena es posterior a la de la tortura del pueblo, ordenada por los reyes.

El carácter intocado del monarca aparecerá bajo otros aspectos en. la figura del rey $\mathrm{D}$. Pedro que nos retrata Calderón en El médico de su honra. Aquí no hay admiración reverencial ni se habla de la hermosura del rey; lo que provoca D. Pedro en sus súbditos es el miedo, un miedo que hace titubear a los soldados que se acercan a él y que deja un círculo de amplio espacio vacío a su alrededor. Concede favores, intenta impartir la justicia, pero su figura termina por no provocar el amor de sus gobernados: insiste en que sea reconocido su territorio por los demás y prescribe el palacio como lugar sagrado. Ante los caballeros que por razones cle honor han tomado las espadas frente a él, exclama:

$$
\begin{aligned}
& \text { Rey ¿Que es esto? } \\
& \text { ¿Cómo las manos tenéis } \\
& \text { en las espadas delante } \\
& \text { de mí? ¿No tembláis de ver } \\
& \text { mi semblante? Donde estoy, } \\
& \text { ¿hay soberbia ni altivez?18 }
\end{aligned}
$$

17 Lope, Fuenteovejuna, III, vv. 2366-2389, ed. López Estrada, Castalia, Madrid, 1973 .

18 Calderón, El médico..., I, vw. 984-989, ed. cit. 
$Y$ es que Pedro el Cruel, es presentado con caracteres terribles: nos lo muestran así su paralelismo por similitud con don Gutierre, ese ser monstruoso dominado por la obsesión del honor, su complicidad con el crimen de Mencía que así concluye sin castigo, sus salidas nocturnas y encubierto. Asimismo, el rey, que había ejercido su papel en el tribunal en el sitio sagrado del palacio, en la última escena de la obra, termina por distribuir la justicia en la calle. En esta obra, Calderón se ha servido de la imagen intocada del monarca para darnos de él una visión distinta a la común de la comedia nueva; no es el rey el representante de la luz y del Bien, tal como aparece en la escena de El burlador de Sevilla, sino un ser que guarda estrechos vínculos con las tinieblas.

De igual forma que los reyes, en el teatro del siglo xvir otros seres parecen haber sido establecidos por una distancia personal mayor, que no guardan personajes comunes. Son las mujeres en general, pero sobre todo, las mujeres casadas. La mujer de otro, como los monarcas, son figuras de "no contacto", lo que explica su reclusión en la casa. De ahí el impacto de ver aparecer en escena a Casandra en brazos de Federico en El castigo sin venganza.

Don Juan, al desplegar la seducción, toma la mano de las mujeres como señal de apoderarse de su cuerpo. Rompe así, el burlador, la esfera personal femenina que pertenece a otro: "Dame esa mano, y esta voluntad confirma", dice, burlándose de esta manera de la sagrada promesa de matrimonio que se da con la mano. Al final, como sabemos, un muerto, la figura fantasmal de don Gonzalo de Ulloa, le pedirá la mano también, para aprisionarla entre la suya y transmitirle el fuego trascendente, para llevarlo a los infiernos:

\begin{tabular}{cl} 
Don Gonzalo & \multicolumn{1}{c}{ Dame esa mano } \\
& No temas, Ia mano dame. \\
Don Juan & ¿Eso dices? ¿Yo temor? \\
& ¿Que me abraso! ¡No me abrases \\
con tu fuego!
\end{tabular}


Las maravillas de Dios son, don Juan, investigables, y asi quiere que tus culpas a manos de un muerto pagues... ${ }^{10}$

El panorama que acabo de esbozax constituye una rápida muestra de que lo que juzgo se puede investigar sobre la simbolización espacial en el teatro del Siglo de Oro español. En ese camino hay muchos aspectos aún por develar, pues el vario universo del topos dramático constituye una veta rica y apasionante. Varios investigadores antes de ahora han tenido atisbos, frecuentemente visiones certeras, sobre el significado del espacio en la Comedia nueva, por lo que no puede afirmarse que nuestra propuesta sea del todo novedosa; pero hay un extenso campo todavía inexplorado del que sólo alcanzamos a plantear algunas preguntas, en espera de unas reflexiones y un análisis que se puedan constituir en un estudio sistemático: ¿en qué puntos difiere la representación dramática del espacio de la que se nos sugiere en una novela? ¿qué elementos significantes se enfatizan en la elección de una "unidad de lugar"? ¿por qué, en ciertos momentos de la historia, la representación de unos espacios - la sala de estar en Ibsen- se prefiere a otros - la cocina de La señorita Julia de Strindberg? etc. La propuesta que se hace aquí de un estudio sistemático, ya se ve, debiera hacer confluir las derivaciones de la investigación filológica, los hallazgos del psicoanálisis en lo que se refiere al proceso de la psique en la simbolización topológica, las ideas al respecto sobre lo sagrado y lo profano, la naturaleza y la cultura que aporta la antropología, los conceptos espaciales que se derivan de la proxémica, las aportaciones sobre el cuerpo de la llamada "nueva comunicación", y claro, las especulaciones sobre la generación de significados y cómo se llega en el teatro (texto + signos de representación) a la simbolización del espacio, aportadas por la semiótica.

10 Tirso de Molina, El burlador de Sevilla, IXI, vv. 2747-2755, ed. Xavier A. Fernández, Alhambra, Madrid, 1982. 